OPEN ACCESS

Edited by:

Sorin Fedeles,

Yale University, United States

Reviewed by:

Astrid Weins,

Harvard Medical School,

United States

Mark Lal,

AstraZeneca, Sweden

*Correspondence:

Shuta Ishibe

shuta.ishibe@yale.edu

Specialty section

This article was submitted to Nephrology,

a section of the journal

Frontiers in Medicine

Received: 25 October 2021 Accepted: 06 January 2022 Published: 10 February 2022

Citation:

Tian X, Bunda P and Ishibe S (2022)

Podocyte Endocytosis in Regulating the Glomerular Filtration Barrier.

Front. Med. 9:801837.

doi: 10.3389/fmed.2022.801837

\section{Podocyte Endocytosis in Regulating the Glomerular Filtration Barrier}

\author{
Xuefei Tian, Patricia Bunda and Shuta Ishibe* \\ Department of Internal Medicine, Yale School of Medicine, New Haven, CT, United States
}

Endocytosis is a mechanism that internalizes and recycles plasma membrane components and transmembrane receptors via vesicle formation, which is mediated by clathrin-dependent and clathrin-independent signaling pathways. Podocytes are specialized, terminally differentiated epithelial cells in the kidney, located on the outermost layer of the glomerulus. These cells play an important role in maintaining the integrity of the glomerular filtration barrier in conjunction with the adjacent basement membrane and endothelial cell layers within the glomerulus. An intact podocyte endocytic machinery appears to be necessary for maintaining podocyte function. De novo pathologic human genetic mutations and loss-of-function studies of critical podocyte endocytosis genes in genetically engineered mouse models suggest that this pathway contributes to the pathophysiology of development and progression of proteinuria in chronic kidney disease. Here, we review the mechanism of cellular endocytosis and its regulation in podocyte injury in the context of glomerular diseases. A thorough understanding of podocyte endocytosis may shed novel insights into its biological function in maintaining a functioning filter and offer potential targeted therapeutic strategies for proteinuric glomerular diseases.

Keywords: proteinuria-nephrotic syndrome, glomerular disease, endocytosis, kidney, podocyte

\section{INTRODUCTION}

The word "endocytosis" initially coined by Christian de Duve in 1963, describes the process of internalization and retrieval of extracellular material including the cellular plasma membrane components and transmembrane receptors via small vesicles. Internalized molecules from the plasma membrane can be recycled back to the cell surface or be degraded in the cell. Endocytosis orchestrates numerous cellular processes, which include membrane formation, cell signal transduction, adhesion, motility, immune response, membrane turnover, lipid homeostasis, uptake of nutrients, and development in response to the ambient environmental changes (1-3). Based on vesicular membrane components and cargoes (4) identified by electron microscopy, endocytic pathways can be broadly divided into clathrin-mediated endocytosis (5), and clathrin-independent endocytosis, which is further subdivided into caveolae-dependent endocytosis (6), phagocytosis (“cell eating") (7, 8), macropinocytosis (“cell drinking”) (9), cholesterol-sensitive pathway $(10,11)$, and clathrin-independent carrier/GPI-AP-enriched early endosomal compartment (CLIC/GEEC) pathway endocytosis (12).

The kidney is composed of glomeruli, tubules, renal interstitium, and renal vasculature that work in unison to remove waste from plasma. The glomerular filtration barrier (GFB) serves as a semi-permeable membrane allowing for free filtration of small solutes while retaining larger solutes such as albumin and immunoglobulin in circulation. The GFB is composed of three layers: the 
podocytes located at the outermost layer facing the Bowman's space, the fenestrated endothelial cells located at the innermost layer facing the glomerular capillary lumen, and the glomerular basement membrane located between them (13). Impaired function or depletion of podocytes contributes to many forms of proteinuric chronic kidney diseases (CKD). CKD currently affects more than 800 million people worldwide and is expected to become more prevalent in the decades to come (14). Moreover, glomerular diseases account for approximately $83 \%$ of cases that progress to end-stage kidney disease (ESKD) according to the United States Renal Data system (https://adr.usrds.org/2020/).

Impaired endocytic pathways in the podocytes have been implicated in the damage of the glomerular filtration barrier. Burgeoning evidence strongly suggests that endocytic pathways play a key role in maintaining proper kidney function. Genetic missense mutations in GAPVD1 and ANKFY1 whose protein products interact with the endosomal regulator RAB5 (2), and missense mutations in TBC1D8B, whose protein product is the Rab1lb-guanosine triphosphatases (GTPase)-activating protein (15) have been found causal in human steroid-resistant nephrotic syndrome. This is complimented by the genetic mouse models of disease where dysfunction in the endocytic process results in severe proteinuria suggesting its importance (Table 1). In this review, we will attempt to describe what is currently known about the podocyte endocytic process highlighting the potential mechanisms involved in maintaining a functioning filtration barrier.

\section{PRINCIPAL ROUTES OF ENDOCYTOSIS Clathrin-Mediated Endocytosis Pathway}

The hallmark of the clathrin-mediated endocytosis pathway (CME) is the involvement of clathrin, a triskelion-shaped protein that assembles in a lattice-like structure. Specific cargos in the clathrin-coated pits are internalized by dynamin-dependent vesicle fission, followed by the clathrin disassembly (28). CME allows the target proteins to be transported to endosomes, which are sorting stations directing endocytosed vesicles to either recycling or degradation pathways. The CME process progresses through a series of well-regulated steps resulting in morphological alterations. First, phosphatidylinositol-4,5bisphosphate [PI $(4,5]$ P2]-enriched regions in the plasma membrane recruit the clathrin adaptor proteins such as AP2, epsin, and dynamin. Second is the recruitment of proteins with Bin-Amphiphysin-Rvs (BAR)-containing domain such as endophilin, which can initiate the clathrin nucleation and polymerization resulting in the growth of the clathrin-coated pits (CCP), to approximately $60-120 \mathrm{~nm}$ in diameter $(3,29-$ 31). Lastly, the formation of clathrin-coated vesicles (CCVs) is generated by the pinching off of CCP from the plasma membrane through GTPase dynamin assembly, GTP hydrolysis, dephosphorylation of [PI (4,5] P2] by synaptojanin. Lastly, uncoating of clathrin and shedding of the CCPs occurs with the help of auxillin/cyclin G-associated kinase (GAK) and hsc70 (32-34).

\section{Clathrin-Independent Endocytosis Pathway}

In order to adapt to the requirements of different cell types, the endocytic machinery in mammals is highly complex. CME alone is likely inadequate to meet this demand (35). Many mechanisms of clathrin-independent endocytosis (CIE) that play a critical role in cell trafficking have been identified and characterized, especially with the development of electron microscopy (4). Eleven types of CIE modes were discovered and identified, including macropinocytosis, phagocytosis, caveolae-dependent endocytosis, arf6-dependent endocytosis, flotillin-dependent endocytosis, CLIC/GEEC-mediated pathway endocytosis, fast endophilin-mediated endocytosis (FEME), ultrafast endocytosis (UFE), activity-dependent bulk endocytosis (ADBE), IL-2R $\beta$ pathway endocytosis, and massive endocytosis $(4,35,36)$. Interestingly, CME and these 11 types of CIE are endocytic pathways that are cholesterol-dependent. Moreover, CME and 6 types of CIE including phagocytosis, caveolae-dependent endocytosis, FEME, ADBE, UFE, IL-2R $\beta$ pathway endocytosis, are dynamin-dependent (35).

Caveolae-dependent endocytosis is one of the most welldescribed CIE pathways in cells including podocytes. Caveolae are named for their resemblance to caves or flask-shaped cholesterol-enriched smooth membrane invaginations that are $50-80 \mathrm{~nm}$ in diameter (37). The integral membrane protein, caveolin-1, and other adaptor proteins of the cavin family are required for this process, in which phosphorylation of caveolin1 initiates the initial budding formation and internalization before dynamin and actin machinery-dependent fission $(4,38)$. Caveolae-dependent endocytic processes have been identified in the endothelial cells, epithelial cells, fibroblasts, adipocytes, and human podocytes $(35,39,40)$, and are found to participate in the trafficking of sphingolipids or proteins through lipid rafts. Downregulation of Wilms tumor 1 (WT1), a podocyte-specific transcription factor, mediates activation of $\mathrm{Wnt} / \beta$-catenin signaling by recruiting LRP6 (LDL Receptor Related Protein 6) to the caveolin-dependent endocytic pathway, resulting in the downregulation of nephrin and induction of apoptosis (41). Flotillin-dependent endocytosis is associated with lipid rafts to select lipid cargo mediated by flotillin through mechanisms that are not well understood $(42,43)$. In addition, the role of dynamin in flotillin-dependent endocytosis also remains unclear. However, studies suggest that this pathway may serve as adaptors in other forms of CIE rather than as an individual endocytic process $(35,44)$. In the CLIC-GEEC endocytosis pathway, proteins such as GPI-anchored aminopeptidases (GPI-APs) are internalized in tubulovesicular structures called GPI-AP enriched early endosomal compartments (GEEC) $(12,45)$. The trafficking of many internalized membrane and fluid-phase contents is endocytosed through CLIC-GEEC endocytic pathway, which is a dynamin-independent $(12,35,46)$. Although CLIC -GEEC pathway does not require dynamin for endocytosis, dynamin is associated with the post-internalization of GEEC (12). Many cytokine receptors are internalized by the IL-2R $\beta$ endocytic pathway, which requires activation of the small GTPases RhoA and Racl, as well as actin polymerization, which finally forms 
TABLE 1 | Loss of function of endocytosis-associated proteins in podocytes resulting in proteinuria.

\begin{tabular}{|c|c|c|}
\hline Protein & Characterization & References \\
\hline $\begin{array}{l}\text { Class II phosphoinositide 3-kinase } \\
\mathrm{C} 2 \alpha(\mathrm{PI} 3 \mathrm{KC} 2 \alpha)\end{array}$ & $\begin{array}{l}\text { PI3KC2 } \alpha \text {-deficient mice cause modest proteinuria, glomerulosclerosis, foot } \\
\text { process effacement, loss of podocytes, and kidney failure }\end{array}$ & $(16)$ \\
\hline $\begin{array}{l}\text { Class III phosphatidylinositol 3-kinase } \\
\text { vacuolar protein sorting } 34 \text { (Vps34) }\end{array}$ & $\begin{array}{l}\text { Podocyte-specific loss of Vps34 leads to early proteinuria, } \\
\text { glomerulosclerosis, foot process effacement, and kidney failure }\end{array}$ & $(17-19)$ \\
\hline Dynamin 1 and Dynamin2 & $\begin{array}{l}\text { Loss of dynamin1 and dynamin2 in mice podocyte cause progressive } \\
\text { proteinuria, glomerulosclerosis, foot process effacement, and kidney failure }\end{array}$ & $(20)$ \\
\hline Synaptojanin1 & $\begin{array}{l}\text { Loss of synpatojanin1 in mice results in severe proteinuria, foot process } \\
\text { effacement }\end{array}$ & $(20)$ \\
\hline Endophilin1, 2 and 3 & $\begin{array}{l}\text { Loss of endophilin 1, } 2 \text {, and } 3 \text { in mice results in severe proteinuria, foot } \\
\text { process effacement }\end{array}$ & $(20)$ \\
\hline CD2-associated protein (CD2AP) & $\begin{array}{l}\text { Loss of CD2AO exhibits proteinuria, glomerulosclerosis, foot process } \\
\text { effacement, and kidney failure }\end{array}$ & $(21)$ \\
\hline Cyclin G-associated kinase (GAK) & $\begin{array}{l}\text { Podocyte-specific loss of Gak causes progressive proteinuria, } \\
\text { glomerulosclerosis, and kidney failure }\end{array}$ & $(22)$ \\
\hline CIN85 & $\begin{array}{l}\text { CIN85 exon2 deletion ameliorates proteinuria and glomerular matrix } \\
\text { accumulation in streptozocin-induced type } 1 \text { diabetic mice; Overexpression } \\
\text { of CIN85 in zebrafish causes severe edema, proteinuria, and effacement of } \\
\text { foot process }\end{array}$ & (23) \\
\hline $\begin{array}{l}\text { Protein kinase } \mathrm{C} \text { alpha }(\mathrm{PKC} \alpha) \text { and } \\
\text { beta }(\mathrm{PKC} \beta)\end{array}$ & $\begin{array}{l}\text { PKC } \alpha \text { inhibitor stabilizes nephrin expression and ameliorates the proteinuria } \\
\text { in streptozocin-induced type } 1 \text { diabetic mice Genetic loss of PKC } \alpha \text { and } \\
\text { PKC } \beta \text { reduce the proteinuria in streptozocin-induced type } 1 \text { diabetic mice } \\
\text { Dual PKC } \alpha \text { and PKC } \beta \text { inhibitor ameliorate the proteinuria in the } \\
\text { streptozocin-induced type } 1 \text { diabetic mice and } d b / d b \text { type } 2 \text { diabetic mice }\end{array}$ & $(24,25)$ \\
\hline Exoc5 (a central exocyst component) & $\begin{array}{l}\text { Podocyte-specific loss of Exoc5 mice exhibit the massive proteinuria, } \\
\text { mislocalization and/or loss of Neph1, Nephrin, foot process effacement and } \\
\text { die within } 4 \text { weeks of age }\end{array}$ & $(26)$ \\
\hline Epsin & $\begin{array}{l}\text { Loss of epsin1, epsin2, and epsin } 3 \text { results in progressive proteinuria, } \\
\text { glomerulosclerosis, and kidney failure }\end{array}$ & $(27)$ \\
\hline
\end{tabular}

vesicles $50-100 \mathrm{~nm}$ in diameter $(47,48)$. The small GTPase ADPribosylation factor 6 (Arf6) is localized at the interface of the plasma membrane and endosomal structure (49), Arf6-GTP activates the phosphatidylinositol-4 phosphate 5-kinase, which is involved in cytoskeleton rearrangement and initiating cargo internalization including the IL-2 receptor $\alpha$-subunit, and $\beta 1$ integrin (50-52).

Phagocytosis engulfs particles larger than $500 \mathrm{~nm}$ into membrane-containing vesicles $0.5-3 \mu \mathrm{m}$ in diameter called phagosomes. Phagocytosis is best characterized by its role in defending against microbial pathogens $(35,53)$. Pinocytosis uptake the contents dissolved in the fluid phase. Pinocytosis has two forms known as micropinocytosis and macropinocytosis which is based on the sizes of generated endocytosed vesicles. Pinocytosis is essential for the cellular absorption of water, nutrients, and ions in the fluid phase $(35,54)$. FEME is a non-constitutive mode of CIE that is triggered following stimulation of G-protein-coupled receptors and cytokine receptors through ligand binding. This process is mediated by pre-existing membrane clusters of endophilin resulting in rapid internalization (5-10 s). FEME is regulated by phosphoinositides and kinases such as Src, LRRK2, Cdk5, and GSK3 $\beta$, and is dynamin-dependent $(35,55)$. The fundamental importance of these pathways remains elusive as genetic knockout models deleting important CIE pathways have not been shown to result in severe proteinuria.

\section{ENDOCYTOSIS IN PODOCYTE HOMEOSTASIS AND DISEASE}

\section{Role of Phosphatidylinositol 4,5-Bisphosphate in Podocyte Endocytosis} Phosphoinositides are membrane lipids generated by phosphorylation on the inositol domain. Phosphatidylinositol 4,5-bisphosphate $(\mathrm{PI}(4,5) \mathrm{P} 2)$ is the most abundant phosphoinositide species enriched at inner leaflets of the cell membrane which is mainly produced by type I and type II phosphatidylinositol-phosphate kinases (PIPKs) (56). PI(4, 5)P2 can also be generated by dephosphorylation of $\mathrm{PI}(3,4,5) \mathrm{P} 3$ mediated by the phosphatase and tensin homolog (PTEN) $(3,57)$. $\mathrm{PI}(4,5) \mathrm{P} 2$ plays an essential role in the regulation of CME $(58)$. $\mathrm{PI}(4,5) \mathrm{P} 2$ promotes the initial step in the CME process by its interaction with clathrin, clathrin adaptors, and its effectors (3). Besides the critical role of PIPKs in the production of $\mathrm{P}(4,5) \mathrm{P} 2$, it also regulates poly-phosphoinositide phosphatase, synaptojanin 1 , which is responsible for dephosphorylation and hydrolysis of PI $(4,5) \mathrm{P} 2(49,59)$. Global loss of synaptojanin1 enhances PI(4, 5)P2 levels and results in an accumulation of clathrin-coated vesicles $(60,61)$. These global knockout mice die early likely due to the inability of the pups to feed properly. Besides its neurologic importance, we have demonstrated that loss of synaptojanin 1 results in proteinuria and extensive podocyte foot process effacement (20). Moreover, the importance of 
phosphoinositides in podocyte biology has been shown through the genetic loss of class II phosphoinositide 3-kinase C2 $\alpha$ (PI3KC2 $\alpha$ ), an enzyme that generates $\mathrm{PI}(3) \mathrm{P}$ and $\mathrm{PI}(3,4) \mathrm{P} 2$. These mutant mice develop proteinuria and kidney failure, along with altered expression of nephrin and synaptopodin in podocytes (16). Deletion of a key endosomal trafficking regulator, the class III phosphatidylinositol (PtdIns) 3-kinase vacuolar protein sorting 34 (Vps34), specifically in podocytes results in aberrant endosomal membrane morphology, early proteinuria, glomerulosclerosis, and foot process effacement (17-19). Vacuolation phenotype is observed when the Vps34 downstream effector PIKfyve is absent. This phenotype is rescued in Vps34-deficient podocytes in the presence of both Vps34 and PIKfyve (19).

Besides CME, studies have indicated that PI $(4,5) \mathrm{P} 2$ may also play important roles in the regulation of CIE. Dynamin and cortactin, a PI(4,5)P2 -binding protein, have been shown to play important roles in caveolin-dependent endocytosis through actin-modulation and plasma membrane-remodeling $(62,63)$. $\mathrm{PI}(4,5) \mathrm{P} 2$ is a downstream effector of GTPase ARF6, which plays an important role in the ARF6-dependent endocytosis pathway (64). Additionally, $\mathrm{PI}(4,5) \mathrm{P} 2$ plays an essential role in macropinocytosis and phagocytosis that are regulated by GTPase Rac1 (64). Yet the role of $\mathrm{PI}(4,5) \mathrm{P} 2$ in CIE has not been well documented in podocytes and serves as an area open for further studies.

\section{Role of Actin Cytoskeleton in Podocyte Endocytosis}

The actin cytoskeleton in podocytes provides architectural and functional support that is critical for the maintenance of a normal GFB (13). The disruption of the actin cytoskeleton is often associated with podocyte damage, manifesting as massive proteinuria, which is a hallmark of many glomerular diseases and is associated with increased progression to CKD (65). Genetic mutations in actin cytoskeleton-interacting proteins have been shown to cause proteinuric CKD. Mutations such as MYO9A (a Rho-GTPase activating protein myosin) (66), MYO1E (nonmuscle class I myosin, myosin 1E) (67), INF2 (a member of the formin family of actin-regulating proteins INF2) (68), $D A M M 2$ (a member of the formin family of actin-regulating proteins DAAM2) (69), ACTN4 (alpha-actinin 4) (70), CD2AP (CD2-associated protein) (71), and ANLN (filamentous actin [Factin] binding protein) (72) have been identified in patients with nephrotic syndrome and histological evidence of focal segmental glomerulosclerosis (FSGS). Recent evidence suggests that the actin cytoskeleton is critical for CME in cells including the podocytes and have been implicated also in $\operatorname{CIE}(35,49)$.

Membrane invagination during CME is mediated by actin polymerized around the endocytic coat in mammalian cells that are dependent on the N-WASP-activated Arp 2/3 complex, an important cortical actin nucleator $(73,74)$. Ultrastructural examination by electron microscopy has demonstrated that the actin filaments localize to the endocytic pit at the early stages of CME while localizing between the endocytic pit and adjacent plasma membrane at the later stages. The actin cytoskeleton network around the invaginated vesicles appears to play a role in force generation by constricting and elongating the endocytic pit, thereby driving it to detach from the plasma membrane (75). The podocyte actin cytoskeleton is highly dynamic and regulated by small GTPases, but the large GTPase dynamin also plays a critical role through binding to and regulating filamentous actin, which is an essential component of the maintenance of normal podocyte foot process architecture.

The importance of dynamin has been demonstrated where cathepsin-mediated dynamin proteolysis results in podocyte defects due to abnormal actin structure (76). Our studies showed that loss of both Dnm1 and Dnm2 specifically in mouse podocytes (Dnm-DKO) exhibited massive proteinuria, progressive glomerulosclerosis, and kidney failure (20). Dynamin-deficient podocytes showed an accumulation of arrested endocytic pits, which contain Arp2/3, indicating a connection between the endocytosis machinery and the actin cytoskeleton (20). Podocyte-specific loss of Dnm1 and Dnm2 resulted in massive tubulation of plasma membrane endocytic clathrin-coated pits with significant accumulation of Arp2/3 and F-actin in Dnm-DKO fibroblasts (77) (Figure 1). Furthermore, Khalil et al demonstrated that there was increased glomerular Dnm1 and Dnm2 expression in Dahl rats prior to the onset of proteinuria. These findings were recapitulated in increased dynamin expression in patient kidney biopsies from various proteinuric CKD including minimal change disease, FSGS, IgA nephropathy, lupus nephritis, and diabetic kidney disease. Hence, there appears to be a minimum level of dynamin that is required for the maintenance of the GFB, and increased expression of dynamins may serve as a compensatory mechanism in response to pathological conditions $(78,79)$.

Dynamin has also been shown to interact with the Arp2/3 (80, 81 ) and directly with actin (82) promoting dynamin to assemble in higher-order structures. This has led to exciting possibilities of promoting actin-dependent dynamin oligomerization by use of the small molecule Bis-T-23 to improve proteinuria and the progression of CKD in various rodent injury and genetic models (83). Mechanistically, Bis T-23 appears to promote actin stress fiber formation and focal adhesion maturation (84).

Dynamin 1 has also been shown to colocalize with microtubule bundles in mouse podocytes, and loss of dynamin1 impairs microtubule formation and stabilization. Furthermore, dynamin1 and dynamin2 double knockout primary mouse podocytes showed rare microtubule-rich protrusions (85).

Non-muscle myosins have been suggested to play a key role in CME. Myosin II is required for clathrin-coated pit curvature progression and normal symmetry (86). Myosin 1E (Myo1E) is an actin-based motor protein, that interacts with dynamin and synaptojanin1 (87) and uses energy from the hydrolysis of adenosine triphosphate (ATP). Myo1E is recruited at late stages of clathrin-coated pits coincident with actin assembly and is required for N-WASP recruitment $(75,88,89)$. Depletion of Myo1E inhibits transferrin endocytosis and extends the lifetimes of clathrin and dynamin on the invaginated vesicles $(86,88)$. Overexpression of MyolE in the mouse podocytes promotes the expression of F-actin and increases albumin endocytosis mediated by dynamin (90). Mutations in MYO1E 


\section{Regulation of actin at clathrin coated pits}

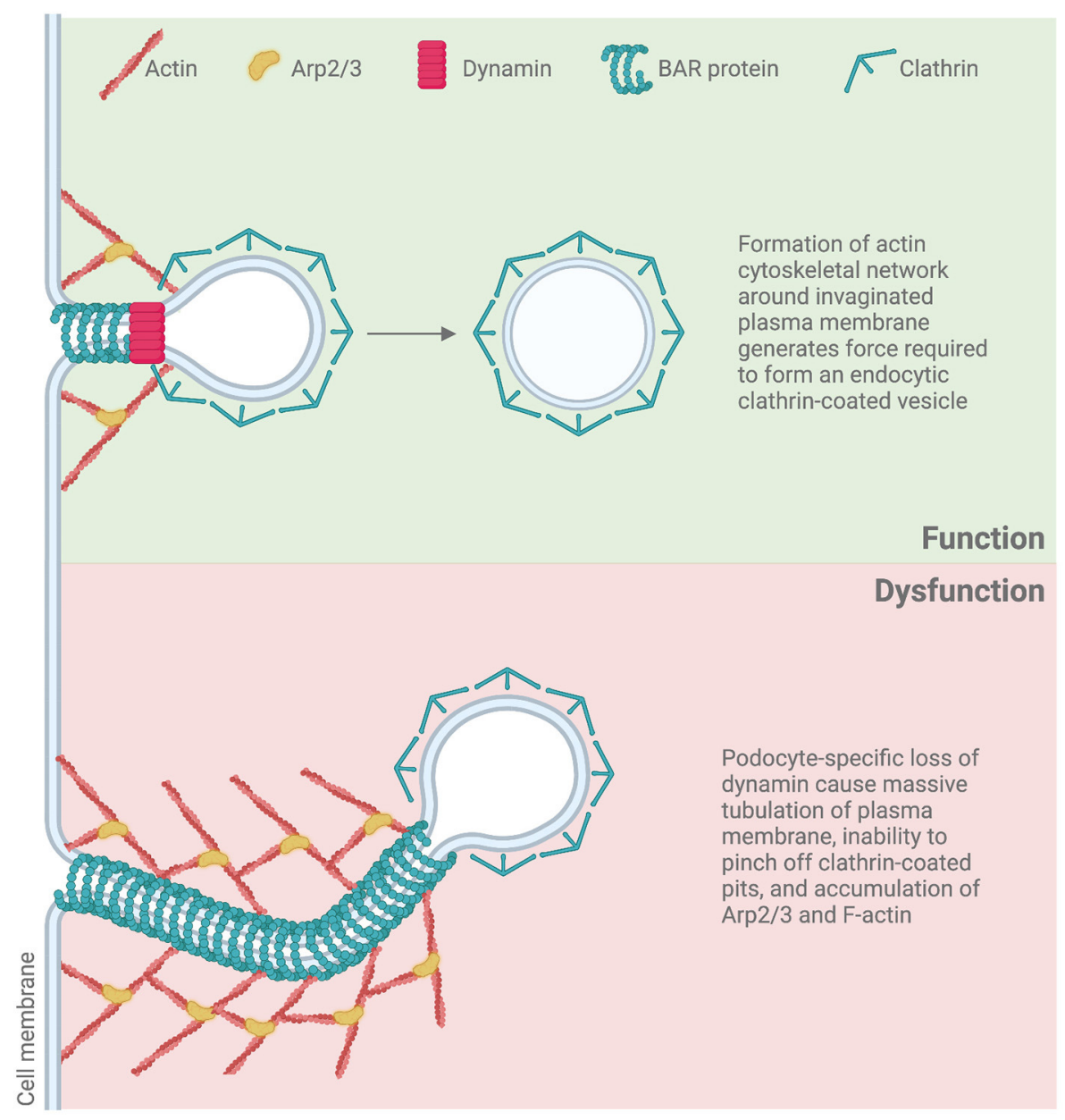

FIGURE 1 | Regulation of actin at clathrin coated pits.

(A159P and Y695X) were reported causing autosomal recessive steroid-resistant FSGS further illustrating the importance of this gene (67).

The non-catalytic region of the tyrosine kinase (Nck) family of adaptors including Nck1 and Nck2, plays key roles in the remodeling of the cytoskeleton (91). Phosphorylation on the tyrosine residues of nephrin promotes the nephrinNck (Nck1/Nck2) complex formation which binds via the $\mathrm{SH} 3$ domain of Nck and results in actin assembly (92). Nck also interacts with GTPase dynamin, lipid phosphatase synaptojanin1, and actin-polymerizing protein N-WASP to regulate the actin assembly and endocytosis $(91,93,94)$.

CD2-associated protein (CD2AP) is a cortactin-binding scaffold protein that controls actin dynamics and participates in membrane trafficking during endocytosis by interacting with dynamin, synaptojanin1, endophilin, and nephrin $(49,95)$. $\mathrm{CD} 2 \mathrm{AP}$ has three Src homology 3 (SH3) domains and a coiledcoil domain contributing to its functions on actin dynamics and endocytosis by interactions with other proteins containing proline-rich domains (96). Interestingly, mice lacking $C d 2 a p$ develop nephrotic syndrome and die at 6-7 weeks of age due to kidney failure (21). Furthermore, it has been observed that human mutations in CD2AP are associated with FSGS $(95,97)$.

More recently, cyclin G-associated kinase (GAK), a ubiquitously expressed kinase that is associated with the uncoating of the clathrin-coated vesicles has been shown to be indispensable in podocytes $(98,99)$. Podocyte-specific Gak mice developed progressive proteinuria, glomerulosclerosis, and kidney failure, due to cytoplasmic calcium dysregulation, aberrant calpain-1/-2 activation, and actin rearrangement (22).

Although the role of the actin cytoskeleton in podocytes has not been fully understood, the actin filament accumulating around the endocytic pits provides the constriction force required for pulling the invaginated vesicles inwards $(92,100)$. Its importance in counteracting the membrane tension caused by the significant stretch and shear strain due to the cell adhesion to the glomerular basement membrane has been solidified. Thus, the intimate link between actin and endocytosis in podocytes 
plays a critical role in maintaining a normally functioning filtration barrier.

\section{Regulation of Slit Diaphragm in Podocyte Endocytosis}

The highly specialized intracellular junctions called slit diaphragm are formed by the interdigitating foot processes of podocytes. The slit diaphragm is an essential part of the glomerular size-selective filtration barrier (13). Podocyte differentiation requires recruitment of the slit diaphragmspecific, neuronal junction proteins to membrane domains, in which endocytic trafficking plays an important role. Hence, the endocytic process regulating a subset of slit diaphragm proteins appears critical to maintaining the integrity of the $\operatorname{GFB}(87,101)$.

Podocin, encoded by the NPHS2, is a membrane-attached protein that is required in maintaining the integrity of the podocyte slit diaphragm (102). In both the puromycin aminonucleoside nephrosis (PAN) and poor-prognosis human IgA nephropathy, endocytic dependent translocation of podocin to the cytoplasm has been demonstrated using immunofluorescence. Furthermore, podocin co-localizing with Rab5 (a key factor in regulating early endocytosis) during podocin internalization has been observed. This suggests podocin trafficking may play a critical role following podocyte injury and contributes to the disruption of the integrity of the GFB (103). The protein sorting nexin 9 (SNX9) interacts with podocin via its C-terminal BAR domain, and SNX9 expression has been shown to colocalize with podocin following adriamycin-induced podocyte injury in vitro and in vivo. Its expression is also upregulated in kidney samples of patients with severe glomerular injury. In addition, SNX9 binds directly to dynamin and stimulates dynamin assembly and GTPase activity. Hence, SNX9 may also play a prominent role in promoting podocin endocytosis by regulating dynamin (104).

Nephrin, encoded by NPHS1, is a podocyte-specific protein and a core component of the slit diaphragm. Proper expression of nephrin on the cell surface is critical in ensuring the integrity of the GFB. Downregulation or mislocalization of nephrin has been indicated in the pathogenesis of proteinuric kidney disease. Human mutations have been found to result in Autosomal Recessive Congenital Nephrotic Syndrome of the Finnish type $(105,106)$. It has been demonstrated that the long isoform of CIN85 (RukL) interacts with nephrin and mediates its endocytosis in podocytes; the paralog CD2AP can also stabilize the slit diaphragm by binding to nephrin (107). CIN85/RukL can regulate ubiquitination and several types of degradative endosomal sorting. Loss of CIN85/RukL preserves the nephrin surface expression on the podocyte slit diaphragm and reduces podocyte loss and proteinuria in the streptozotocininduced type 1 diabetic mice. On the contrary, overexpression of CIN85/RukL in zebrafish results in severe edema and proteinuria (23). Protein kinase $\mathrm{C}$ (PKC) and casein kinase 2 substrate in neurons 2 (PACSIN2), also known as syndapin II, is a member of the Bin-Amphiphysin-Rvs (BAR) family that contains an evolutionary membrane binding and sculpting domain. PACSIN2 can accelerate endocytosis and intracellular trafficking of nephrin via the involvement of rabenosyn-5, which is involved in early endosome maturation and endosomal sorting (108). PKC $\alpha$, one of the PKC isoforms, has been implicated in the endocytic process. Elevated PKC $\alpha$ levels in podocytes result in enhanced endocytosis of nephrin and instability of the slit diaphragm, which may play an important role in the development of albuminuria in the diabetic mice model (109). Treatment with PKC $\alpha$ inhibitors preserved podocyte nephrin retention and reduced proteinuria in type 1 diabetic mice (24). Thus, PKC $\alpha$ and PKC $\beta$ inhibitors may play a salutary role in alleviating the preexisting albuminuria in both types I and type II diabetic mice (25). The phosphotyrosine adaptor protein ShcA promotes nephrin endocytosis by increasing the tyrosine phosphorylation of nephrin resulting in aberrant nephrin turnover and distribution within the slit diaphragm (110). Podocyte ShcA expression was found to increase when co-stained with nephrin in IgA nephropathy, minimal change disease, and FSGS kidney biopsy specimens (108).

Human missense mutations of GAPVD1 were identified in patients with early-onset steroid-resistant nephrotic syndrome using the whole-exome sequence. Mutated GAPVD1 reduced nephrin binding and clathrin uncoating via RAB5 regulation, resulting in impaired endocytosis and nephrin mistrafficking which was confirmed by the silencing Gapvd1 in drosophila (2). The deletions of exocyst 4 (EXOC4), one of the highly conserved octameric proteins of the exocyst trafficking complex which mediates the targeting and docking of endocytosed vesicles, was also identified in patients with nephrotic syndrome. Podocytespecific loss of Exoc5 (a central exocyst component interacting with Exoc4) in mice showed massive proteinuria, severe glomerulosclerosis, and fibrosis. In addition, mislocalization and/or loss of nephrin and neph1 expression were observed and this was implicated as a major contributor to this phenotype. This suggests the presence of an important mechanism that regulates the trafficking of nephrin and neph 1 can help maintain an intact filtration barrier (26). Moreover, IQ domain GTPaseactivating protein 1 (IQGAP1), a scaffold protein containing multiple protein-binding domains that act as a polymerization platform for a variety of proteins and signaling kinases, mediates nephrin endocytosis and has been shown to play a functional role in diabetic kidney disease (111).

Using site-directed mutagenesis, various biochemical methods, single-plane illumination microscopy, and a human nephrin-expressing zebrafish model, canonical YXXØ-type motif, $\mathrm{Y}^{1139} \mathrm{RSL}$, was demonstrated as an endocytic motif for clathrin-mediated nephrin endocytosis. $\mathrm{Y}^{1139} \mathrm{RSL}$ motifmediated endocytosis facilitates nephrin delivery leading to foot process organization and a functional slit diaphragm in a human nephrin-expressing zebrafish model (112). Phosphorylation (activation) and dephosphorylation (deactivation) of nephrin have been identified as an essential posttranslational event that maintains proper podocyte structure and function. Nephrin tyrosine residue phosphorylation by Src family kinases Fyn and Yes, promotes Nck adaptor protein binding mediating actin polymerization and facilitating the endocytic process $(92,113,114)$. Nck's SH3 domains also play a role in coupling dynamin to nephrin, as it allows dynamin to 


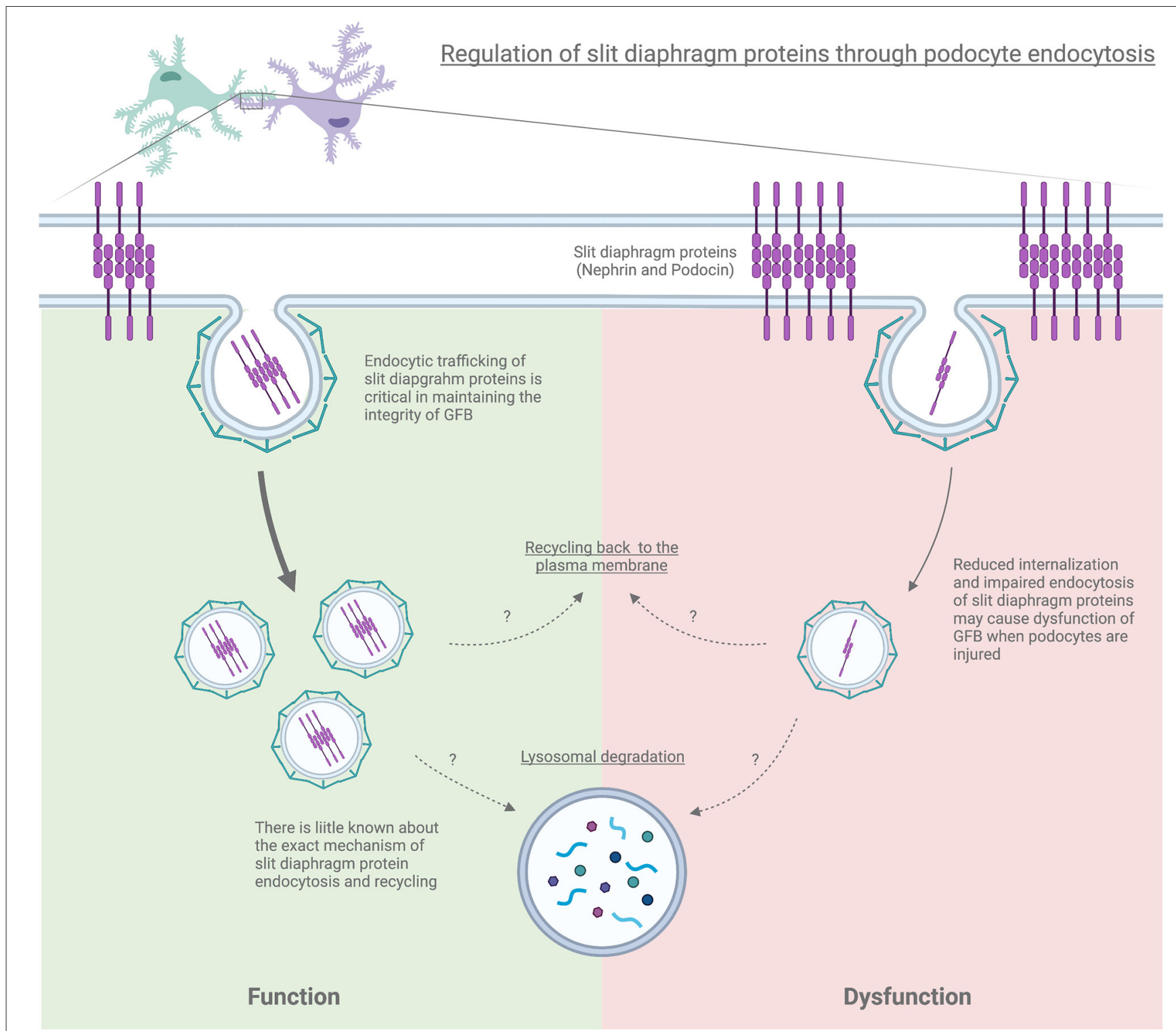

FIGURE 2 | Regulation of slit diaphragm proteins through podocyte endocytosis.

bind through its proline-rich domain. Increased nephrin tyrosine phosphorylation upon podocyte injury correlates with a decreased membrane surface nephrin. Interestingly, mice lacking-Nck binding sites on nephrin are resistant to podocyte injury, which suggests that nephrin-Nck interaction regulates the nephrin endocytosis at the slit diaphragm (92). Nephrin has also been shown to undergo caveolin-dependent endocytosis (20) and CIE (raft-mediated endocytosis) (115). It is postulated that dephosphorylated nephrin appears to be involved in caveolindependent endocytosis, while phosphorylated nephrin seems to participate in the raft-mediated endocytosis (115).

Podocytes exhibit apicobasal polarity, which maintains the fundamental function of podocyte biology. The apical polarity determinants of the partitioning defective-3 (PAR-3) and atypical protein kinase $\mathrm{C}(\mathrm{aPKC})$ are in the form PAR/aPKC complex (Par3/Par6/aPKC), and this complex regulates tight junction formation and slit diaphragm assembly. The RNAi-mediated knockdown of PAR-complex proteins in Drosophila nephrocytes, a model of vertebrate podocytes, causes a severe endocytic defect due to impaired localization of aPKC at the plasma membrane. This results in impaired slit diaphragm localization. In contrast, the knockdown of Scribble, one of the lateral polarity regulators of nephrocytes, also leads to a severe reduction in endocytosis. These results suggest that apical polarity determinants are important for endocytosis and slit diaphragm homeostasis. Basolateral polarity regulators are also critical for mammalian nephrin homolog Sns localization in Drosophila (116). Basolateral polarity proteins- Discs large, 


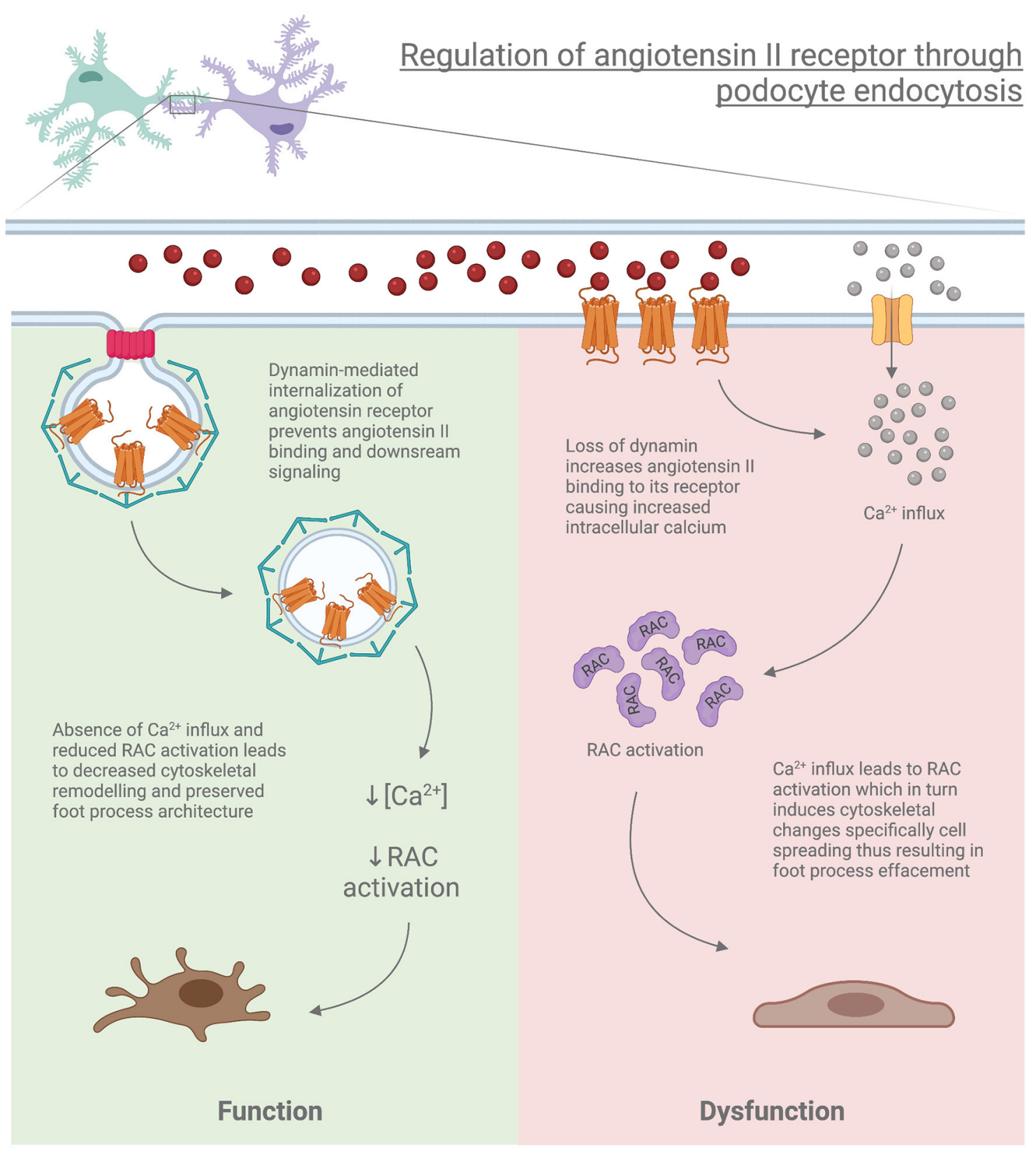

FIGURE 3 | Regulation of angiotensin II receptor through podocyte endocytosis.

Scribble, Lethal giant larvae, and Par-1 are important for normal endocytic trafficking of slit diaphragm proteins including zonula occludens-1 (ZO-1), which was confirmed by colocalization with early endosome Rab5, recycling endosome Rab7, and late endosome Rab11, respectively. The critical importance of ZO-1 in podocyte biology was recently shown when mice with podocyte-specific Zo-1 knockout mice exhibited extensive proteinuria and kidney failure along with disruption of the slit diaphragm (117). ZO-1 is mislocalized from the plasma membrane to the cytosol following lipopolysaccharide or protamine sulfate-induced podocyte injury (118). Loss of basolateral polarity proteins led to slit diaphragm protein mislocalization into the cytoplasmic vesicles of nephrocytes. This suggests that the basolateral polarity is critical for slit diaphragm recycling (119).

Surface expression and turnover of podocin and nephrin appear to be intimately connected. A missense mutation in podocin cause retention of both podocin and nephrin in the cytoplasm $(120,121)$. Factors influencing nephrin and podocin turnover may destabilize the slit diaphragm resulting in subsequent disruption of the glomerular filtration barrier (Figure 2). However, precisely how disruption of 
endocytic trafficking cause defects in the slit diaphragm requires further investigation.

\section{Regulation of Filtered Proteins in Podocyte Endocytosis}

Albuminuria is a hallmark of proteinuric chronic kidney disease and is usually caused by dysfunction of glomerular filtration barrier integrity. Interestingly, albumin endocytosis is enhanced in the podocytes from minimal change disease patients. Accumulation of blue-labeled albumin endocytic vesicles was observed in the podocytes in a rat model of puromycin aminonucleoside-induced nephrotic syndrome (122). Furthermore, overexpression of Myole may also enhance dynamin-mediated albumin endocytosis in mouse podocytes (90). Ang II enhances the migration of albumin-containing vesicles from the glomerular capillary to the apical aspect of the podocyte, which is eventually released into the urinary space. This increase in endocytosis and transcytosis of plasma albumin by podocytes, which is regulated by Ang II, may potentially play a critical role in the formation of proteinuria (123). The caveolaedependent albumin endocytosis has been demonstrated in cultured immortalized human podocytes (39). Filtered albumin enters into the podocyte through Fc-receptors, and reaches the early endosome where albumin is sorted for lysosomal degradation or exocytosed outside of the podocytes (124).

Lipid endocytosis in podocytes has also been implicated to reduce cellular integrity and worsens proteinuria and kidney damage, such as in obesity-related glomerulopathy. Enhanced lipid endocytosis by podocytes from patients with obesityrelated glomerulopathy was observed and was associated with decreased expression of phosphatase and tensin homolog (PTEN). Silencing of PTEN promoted low-density lipoprotein endocytosis in mouse podocytes, while PTEN overexpression inhibited the endocytosis of podocyte lipoproteins. PTEN directly dephosphorylates and activates the actin-depolymerizing factor cofilin-1, leading to depolymerization of F-actin, which is necessary for endocytosis. Inhibition of PTEN resulted in the phosphorylation and inactivation of cofilin-1, leading to Factin formation that enhanced the endocytosis of lipoproteins in podocytes (125). Moreover, free fatty acid (FFA) associated with albumin has been shown to stimulate micropinocytosis through FFA receptors during Adriamycin-induced podocyte injury worsening albuminuria (126).

Mutations in CLCN5, encoding the chloride channel $\mathrm{Cl}^{-} / \mathrm{H}^{+}$exchanger $\mathrm{ClC}-5$, have been identified in FSGS patients with Dent disease using exome sequencing. CLCN5 has been shown also to be expressed in cultured human podocytes. Knockdown of CLCN5 in human podocytes resulted in defective transferrin endocytosis, which suggests that CLCN5 plays a critical role in podocyte function by participating in endocytosis, although the role of targeted cargoes needs to be further investigated podocytes (127).

The apolipoprotein L1 (APOL1) gene (APOL1) variants such as its G1 and G2 alleles are associated with increased risk for nephropathy progression in African Americans including FSGS and human immunodeficiency virus-associated nephropathy (HIVAN). Exogenous recombinant APOL1 can be taken up by human podocytes in vitro via clathrin-dependent endocytosis, contributing to the accumulation of APOL1 in podocytes and may be partially involved in the APOL1-associated renal toxicity, particularly with the G1 and G2 disease variants (128). However, cytotoxicity and effective endocytosis through a clathrin-dependent pathway were not observed in HEK293T cells (129). This discrepancy may be related to the use of different cells or different experimental conditions. Thus, the role of APOL1 endocytosis in podocytes and APOL1-associated renal toxicity is worthy of further studies.

\section{Altered Cell Signaling Pathways Due to Defective Podocyte Endocytosis}

Under hyperglycemic conditions, enhanced recruitment of membranous protein kinase C- $\alpha$ (PKC- $\alpha$ ) facilitates epidermal growth factor receptor (EGFR) ubiquitination and endocytosis, resulting in podocyte extracellular signal-regulated kinase (ERK) induced cellular damage in diabetic kidney disease models. Inhibiting PKC- $\alpha$ or ubiquitin-activating enzyme activation attenuates EGFR internalization and mitigates the high-glucoseinduced podocyte injury (130). Epsins, a family of membrane proteins acting as endocytic adaptors, also play a critical role in the CME and CIE. In mammals, there are three different epsins namely, epsin1 (encoded by Epn1), espin2(encoded by Epn2), and espin3(encoded by Epn3). Podocyte-specific loss of epsins resulted in increased albuminuria and foot process effacement. Primary podocytes isolated from these knockout mice exhibited abnormalities in cell adhesion and spreading, which can likely be attributed to reduced activation of cell division control protein 42 homolog (Cdc42) and serum response factor (SRF), resulting in diminished $\beta 1$ integrin expression in the podocyte (27).

Another facet of the importance of dynamin and the endocytic process is through its role in the internalization of membrane-bound receptors such as Angiotensin II receptor type I (AT1R), which is internalized by CME. Podocytespecific deletion of the ATlaR (Angiotensin II receptor type la which is mainly expressed in mice kidney) in Dnm-DKO mice demonstrated reduced albuminuria, improvement in both glomerulosclerosis and kidney function, and attenuation of membrane abnormalities. Furthermore, isolation of podocytes from Dnm-DKO mice revealed abnormal membrane dynamics, with increased Racl activation and lamellipodial extension, which was attenuated in Dnm-DKO podocytes lacking AT1aR (131). This suggests that loss of endocytic pathways may alter the internalization of receptors such as ATlaR, leading to the continued activation of this pathway contributing to worsened proteinuria and podocyte damage (Figure 3).

Clathrin-dependent and -independent pathways also contribute to $\beta 1$ integrin endocytosis (132). Integrins are a family of transmembrane receptors that integrate cell adhesion to the extracellular matrix with a dynamic link of the cellular cytoskeleton and are important for a plethora of physiological and pathophysiological roles in podocytes. Podocyte-specific loss of integrin $\alpha 3$ or $\beta 1$ in mice causes massive proteinuria 
and foot process effacement $(133,134)$. Integrins are subject to endocytosis and endosomal recycling back to the plasma membrane to maintain their turnover allowing for adaptive adhesive behavior responding to the microenvironment. PEA15 (Phosphoprotein Enriched in Astrocytes of $15 \mathrm{kDa}$ ) is a member of the Death Effector Domain (DED) family, which can regulate $\alpha 5 \beta 1$ integrin endocytosis by interacting with $\beta 1$ integrin cytoplasmic domains as a key endosomal adaptor, hence facilitating cell motility (135). Plasminogen activator inhibitor type-1 (PAI-1) / urokinase plasminogen activator (uPA) complex-mediated uPAR-dependent endocytosis of $\beta 1$ integrin can also cause podocyte injury and progressive podocytes loss (136). The endocytic machinery for $\beta 1$ integrin is potentially through clathrin- and dynamin-independent endocytic route (CLIC-GEEC) via swiprosin-1 (Swip1) and small GTPase Rab21 (137). These findings provide new insight into understanding the endocytic role in cell signaling and how it plays an important role in podocyte injury.

\section{CONCLUDING REMARKS}

It has been established that podocyte proteins are uniquely organized to maintain the integrity of the GFB and its function. and genetic mouse models have validated its importance Table 1. However, the underlying mechanisms that participate in trafficking these proteins to the appropriate location in health and disease states need to be further studied in order to unravel complex pathophysiological relationships. Identifying these mechanisms will likely contribute to developing potential novel therapeutical targets to abate proteinuric

\section{REFERENCES}

1. Ellinger I, Pietschmann P. Endocytosis in health and disease-a thematic issue dedicated to Renate Fuchs. Wien Med Wochenschr. (2016) 166:1935. doi: 10.1007/s10354-016-0454-1

2. Hermle T, Schneider R, Schapiro D, Braun DA, van der Ven AT, Warejko JK, et al. GAPVD1 and ANKFY1 mutations Implicate RAB5 regulation in nephrotic syndrome. J Am Soc Nephrol. (2018) 29:212338. doi: 10.1681/ASN.2017121312

3. Li S, Ghosh C, Xing Y, Sun Y. Phosphatidylinositol 4,5-bisphosphate in the control of membrane trafficking. Int J Biol Sci. (2020) 16:276174. doi: 10.7150/ijbs.49665

4. Doherty GJ, McMahon HT. Mechanisms of endocytosis. Annu Rev Biochem. (2009) 78:857-902. doi: 10.1146/annurev.biochem.78.081307.110540

5. Roth TF, Porter KR. Yolk protein uptake in the oocyte of the mosquito aedes aegypti. L. J Cell Biol. (1964) 20:313-32. doi: 10.1083/jcb.20.2.313

6. Yamada E. The fine structure of the gall bladder epithelium of the mouse. $J$ Biophys Biochem Cytol. (1955) 1:445-58. doi: 10.1083/jcb.1.5.445

7. Vaughan RB. The romantic rationalist: a study of elie metchnikoff. Med Hist. (1965) 9:201-15. doi: 10.1017/S00257273000 30702

8. Tauber AI. Metchnikoff and the phagocytosis theory. Nat Rev Mol Cell Biol. (2003) 4:897-901. doi: 10.1038/nrm 1244

9. Schmid SL, Sorkin A, Zerial M. Endocytosis: past, present, and future. Cold Spring Harb Perspect Biol. (2014) 6:a022509. doi: 10.1101/cshperspect.a022509

10. Mayor S, Parton RG, Donaldson JG. Clathrin-independent pathways of endocytosis. Cold Spring Harb Perspect Biol. (2014) 6:a016758. doi: 10.1101/cshperspect.a016758
CKD. Given the observations that neonatal Fc receptor $(\mathrm{FcRn})$ expression in human podocytes is increased with proteinuric $\mathrm{CKD}$, a nanoparticle-containing albumin and glucocorticoid molecules can be taken up by FcRn receptormediated endocytosis. This aims to decrease or avoid the systemic side effects caused by the clinical glucocorticoids administration (138). Moreover, with some of the most abundant podocyte-specific cargoes identified through mass spectrometry (139), future studies should enlighten critical pathways regulated by podocytes. In conclusion, these current cutting-edge findings on the relationship between endocytosis and podocyte biology will help us to further understand the precise mechanism of podocyte injury and provide impetus to find novel and useful therapeutic approaches to target abnormal endocytic machinery.

\section{AUTHOR CONTRIBUTIONS}

$\mathrm{XT}, \mathrm{PB}$, and SI all participated in writing the manuscript.

\section{FUNDING}

This study was supported by the U.S. National Institute of Health grants DK083294 and DK093269 to SI.

\section{ACKNOWLEDGMENTS}

We apologize to investigators whose published articles could not be cited due to word limitations.
11. Hansen SH, Sandvig K, van Deurs B. The preendosomal compartment comprises distinct coated and noncoated endocytic vesicle populations. J Cell Biol. (1991) 113:731-41. doi: 10.1083/jcb.113.4.731

12. Kirkham M, Fujita A, Chadda R, Nixon SJ, Kurzchalia TV, Sharma DK, et al. Ultrastructural identification of uncoated caveolin-independent early endocytic vehicles. J Cell Biol. (2005) 168:465-76. doi: 10.1083/jcb.200407078

13. Tian X, Ishibe S. Targeting the podocyte cytoskeleton: from pathogenesis to therapy in proteinuric kidney disease. Nephrol Dial Transplant. (2016) 31:1577-83. doi: 10.1093/ndt/gfw021

14. Vart P, Powe NR, McCulloch CE, Saran R, Gillespie BW, Saydah S, et al. National trends in the prevalence of chronic kidney disease among racial/ethnic and socioeconomic status groups, 1988-2016. JAMA Netw Open. (2020) 3:e207932. doi: 10.1001/jamanetworkopen.2020.7932

15. Dorval G, Kuzmuk V, Gribouval O, Welsh GI, Bierzynska A, Schmitt A, et al. TBC1D8B loss-of-function mutations lead to X-linked nephrotic syndrome via defective trafficking pathways. Am J Hum Genet. (2019) 104:348-55. doi: 10.1016/j.ajhg.2018.12.016

16. Harris DP, Vogel P, Wims M, Moberg K, Humphries J, Jhaver KG, et al. Requirement for class II phosphoinositide 3-kinase C2alpha in maintenance of glomerular structure and function. Mol Cell Biol. (2011) 31:63-80. doi: 10.1128/MCB.00468-10

17. Bechtel W, Helmstadter M, Balica J, Hartleben B, Kiefer B, Hrnjic F, et al. Vps34 deficiency reveals the importance of endocytosis for podocyte homeostasis. J Am Soc Nephrol. (2013) 24:727-43. doi: 10.1681/ASN.2012070700

18. Chen J, Chen MX, Fogo AB, Harris RC, Chen JK. mVps34 deletion in podocytes causes glomerulosclerosis by disrupting intracellular vesicle trafficking. J Am Soc Nephrol. (2013) 24:198-207. doi: 10.1681/ASN.2012010101 
19. Venkatareddy M, Verma R, Kalinowski A, Patel SR, Shisheva A, Garg P. Distinct requirements for vacuolar protein sorting 34 downstream effector phosphatidylinositol 3-phosphate 5-kinase in podocytes versus proximal tubular cells. J Am Soc Nephrol. (2016) 27:2702-19. doi: 10.1681/ASN.2015050555

20. Soda K, Balkin DM, Ferguson SM, Paradise S, Milosevic I, Giovedi S, et al. Role of dynamin, synaptojanin, and endophilin in podocyte foot processes. $J$ Clin Invest. (2012) 122:4401-11. doi: 10.1172/JCI65289

21. Shih NY, Li J, Karpitskii V, Nguyen A, Dustin ML, Kanagawa O, et al. Congenital nephrotic syndrome in mice lacking CD2-associated protein. Science. (1999) 286:312-5. doi: 10.1126/science.286.5438.312

22. Tian $\mathrm{X}$, Inoue $\mathrm{K}$, Zhang $\mathrm{Y}$, Wang $\mathrm{Y}$, Sperati CJ, Pedigo CE, et al. Inhibiting calpain 1 and 2 in cyclin $G$ associated kinaseknockout mice mitigates podocyte injury. JCI Insight. (2020) 5:e142740. doi: 10.1172/jci.insight.142740

23. Teng B, Schroder P, Muller-Deile J, Schenk H, Staggs L, Tossidou I, et al. CIN85 deficiency prevents nephrin endocytosis and proteinuria in diabetes. Diabetes. (2016) 65:3667-79. doi: 10.2337/db16-0081

24. Tossidou I, Teng B, Menne J, Shushakova N, Park JK, Becker JU, et al. Podocytic PKC-alpha is regulated in murine and human diabetes and mediates nephrin endocytosis. PLoS ONE. (2010) 5:e10185. doi: 10.1371/journal.pone.0010185

25. Menne J, Shushakova N, Bartels J, Kiyan Y, Laudeley R, Haller H, et al. Dual inhibition of classical protein kinase $\mathrm{C}$-alpha and protein kinase Cbeta isoforms protects against experimental murine diabetic nephropathy. Diabetes. (2013) 62:1167-74. doi: 10.2337/db12-0534

26. Nihalani D, Solanki AK, Arif E, Srivastava P, Rahman B, Zuo X, et al. Disruption of the exocyst induces podocyte loss and dysfunction. J Biol Chem. (2019) 294:10104-19. doi: 10.1074/jbc.RA119.008362

27. Wang Y, Pedigo CE, Inoue K, Tian X, Cross E, Ebenezer K, et al. Murine epsins play an integral role in podocyte function. J Am Soc Nephrol. (2020) 31:2870-86. doi: 10.1681/ASN.2020050691

28. Ramanan V, Agrawal NJ, Liu J, Engles S, Toy R, Radhakrishnan R. Systems biology and physical biology of clathrin-mediated endocytosis. Integr Biol (Camb). (2011) 3:803-15. doi: 10.1039/clib00036e

29. Kaksonen M, Roux A. Mechanisms of clathrin-mediated endocytosis. Nat Rev Mol Cell Biol. (2018) 19:313-26. doi: 10.1038/nrm.2017.132

30. Gallop JL, Jao CC, Kent HM, Butler PJ, Evans PR, Langen R, et al. Mechanism of endophilin N-BAR domain-mediated membrane curvature. EMBO J. (2006) 25:2898-910. doi: 10.1038/sj.emboj.7601174

31. Praefcke GJ, Ford MG, Schmid EM, Olesen LE, Gallop JL, PeakChew SY, et al. Evolving nature of the AP2 alpha-appendage hub during clathrin-coated vesicle endocytosis. EMBO J. (2004) 23:437183. doi: 10.1038/sj.emboj.7600445

32. Soda K, Ishibe S. The function of endocytosis in podocytes. Curr Opin Nephrol Hypertens. (2013) 22:432-8. doi: 10.1097/MNH.0b013e3283624820

33. McMahon HT, Boucrot E. Molecular mechanism and physiological functions of clathrin-mediated endocytosis. Nat Rev Mol Cell Biol. (2011) 12:51733. doi: $10.1038 / \mathrm{nrm} 3151$

34. Marks B, Stowell MH, Vallis Y, Mills IG, Gibson A, Hopkins CR, et al. GTPase activity of dynamin and resulting conformation change are essential for endocytosis. Nature. (2001) 410:231-5. doi: 10.1038/35065645

35. Charpentier JC, King PD. Mechanisms and functions of endocytosis in T cells. Cell Commun Signal. (2021) 19:92. doi: 10.1186/s12964-021-00766-3

36. Thomas B, Matsushita K, Abate KH, Al-Aly Z, Arnlov J, Asayama K, et al. Global cardiovascular and renal outcomes of reduced GFR. J Am Soc Nephrol. (2017) 28:2167-79. doi: 10.1681/ASN.2016050562

37. Pelkmans L, Helenius A. Endocytosis via caveolae. Traffic. (2002) 3:31120. doi: 10.1034/j.1600-0854.2002.30501.x

38. Monier S, Parton RG, Vogel F, Behlke J, Henske A, Kurzchalia TV. VIP21caveolin, a membrane protein constituent of the caveolar coat, oligomerizes in vivo and in vitro. Mol Biol Cell. (1995) 6:911-27. doi: 10.1091/mbc.6.7.911

39. Dobrinskikh E, Okamura K, Kopp JB, Doctor RB, Blaine J. Human podocytes perform polarized, caveolae-dependent albumin endocytosis. Am J Physiol Renal Physiol. (2014) 306:F941-51. doi: 10.1152/ajprenal.00532.2013

40. Kovtun O, Tillu VA, Ariotti N, Parton RG, Collins BM. Cavin family proteins and the assembly of caveolae. J Cell Sci. (2015) 128:126978. doi: $10.1242 /$ jcs. 167866
41. Jing Z, Wei-jie Y, Yi-Feng ZG. Down-regulation of Wt1 activates Wnt/beta-catenin signaling through modulating endocytic route of LRP6 in podocyte dysfunction in vitro. Cell Signal. (2015) 27:1772-80. doi: 10.1016/j.cellsig.2015.05.018

42. Frick M, Bright NA, Riento K, Bray A, Merrified C, Nichols BJ Coassembly of flotillins induces formation of membrane microdomains, membrane curvature, and vesicle budding. Curr Biol. (2007) 17:11516. doi: 10.1016/j.cub.2007.05.078

43. Glebov OO, Bright NA, Nichols BJ. Flotillin-1 defines a clathrin-independent endocytic pathway in mammalian cells. Nat Cell Biol. (2006) 8:4654. doi: $10.1038 /$ ncb 1342

44. Otto GP, Nichols BJ. The roles of flotillin microdomains-endocytosis and beyond. J Cell Sci. (2011) 124(Pt 23):3933-40. doi: 10.1242/jcs.092015

45. Sabharanjak S, Sharma P, Parton RG, Mayor S. GPI-anchored proteins are delivered to recycling endosomes via a distinct cdc42regulated, clathrin-independent pinocytic pathway. Dev Cell. (2002) 2:411-23. doi: 10.1016/S1534-5807(02)00145-4

46. Chaudhary N, Gomez GA, Howes MT, Lo HP, McMahon KA, Rae JA, et al. Endocytic crosstalk: cavins, caveolins, and caveolae regulate clathrin-independent endocytosis. PLoS Biol. (2014) 12:e1001832. doi: 10.1371/journal.pbio.1001832

47. Basquin $\mathrm{C}$, Trichet $\mathrm{M}$, Vihinen $\mathrm{H}$, Malarde V, Lagache $\mathrm{T}$, Ripoll $\mathrm{L}$, et al. Membrane protrusion powers clathrin-independent endocytosis of interleukin-2 receptor. EMBO J. (2015) 34:214761. doi: 10.15252/embj.201490788

48. Grassart A, Dujeancourt A, Lazarow PB, Dautry-Varsat A, Sauvonnet N. Clathrin-independent endocytosis used by the IL2 receptor is regulated by Rac1, Pak1 and Pak2. EMBO Rep. (2008) 9:356-62. doi: 10.1038/embor.2008.28

49. Inoue $\mathrm{K}$, Ishibe $\mathrm{S}$. Podocyte endocytosis in the regulation of the glomerular filtration barrier. Am J Physiol Renal Physiol. (2015) 309:F398405. doi: 10.1152/ajprenal.00136.2015

50. Brown FD, Rozelle AL, Yin HL, Balla T, Donaldson JG. Phosphatidylinositol 4,5-bisphosphate and Arf6-regulated membrane traffic. J Cell Biol. (2001) 154:1007-17. doi: 10.1083/jcb.200103107

51. Donaldson JG, Radhakrishna H. Expression and properties of ADPribosylation factor (ARF6) in endocytic pathways. Methods Enzymol. (2001) 329:247-56. doi: 10.1016/S0076-6879(01)29085-5

52. Honda A, Nogami M, Yokozeki T, Yamazaki M, Nakamura H, Watanabe $\mathrm{H}$, et al. Phosphatidylinositol 4-phosphate 5-kinase alpha is a downstream effector of the small G protein ARF6 in membrane ruffle formation. Cell. (1999) 99:521-32. doi: 10.1016/S0092-8674(00)81540-8

53. Rosales C, Uribe-Querol E. Phagocytosis: a fundamental process in immunity. Biomed Res Int. (2017) 2017:9042851. doi: 10.1155/2017/9042851

54. King JS, Kay RR. The origins and evolution of macropinocytosis. Philos Trans R Soc Lond B Biol Sci. (2019) 374:20180158. doi: 10.1098/rstb.2018.0158

55. Casamento A, Boucrot E. Molecular mechanism of fast endophilin-mediated endocytosis. Biochem J. (2020) 477:2327-45. doi: 10.1042/BCJ20190342

56. Doughman RL, Firestone AJ, Anderson RA. Phosphatidylinositol phosphate kinases put $\mathrm{PI} 4,5 \mathrm{P}(2)$ in its place. J Membr Biol. (2003) 194:7789. doi: $10.1007 / \mathrm{s} 00232-003-2027-7$

57. Bunney TD, Katan M. Phosphoinositide signalling in cancer: beyond PI3K and PTEN. Nat Rev Cancer. (2010) 10:342-52. doi: 10.1038/nrc2842

58. Zoncu R, Perera RM, Sebastian R, Nakatsu F, Chen H, Balla T, et al. Loss of endocytic clathrin-coated pits upon acute depletion of phosphatidylinositol 4,5-bisphosphate. Proc Natl Acad Sci USA. (2007) 104:3793-8. doi: 10.1073/pnas.0611733104

59. Cremona O, Di Paolo G, Wenk MR, Luthi A, Kim WT, Takei K, et al. Essential role of phosphoinositide metabolism in synaptic vesicle recycling. Cell. (1999) 99:179-88. doi: 10.1016/S0092-8674(00)81649-9

60. Perera RM, Zoncu R, Lucast L, De Camilli P, Toomre D. Two synaptojanin 1 isoforms are recruited to clathrin-coated pits at different stages. Proc Natl Acad Sci USA. (2006) 103:19332-7. doi: 10.1073/pnas.06097 95104

61. Mani M, Lee SY, Lucast L, Cremona O, Di Paolo G, De Camilli P, et al. The dual phosphatase activity of synaptojanin1 is required for both efficient synaptic vesicle endocytosis and reavailability at nerve terminals. Neuron. (2007) 56:1004-18. doi: 10.1016/j.neuron.2007.10.032 
62. Sauvonnet N, Dujeancourt A, Dautry-Varsat A. Cortactin and dynamin are required for the clathrin-independent endocytosis of gammac cytokine receptor. J Cell Biol. (2005) 168:155-63. doi: 10.1083/jcb.200406174

63. Cao H, Orth JD, Chen J, Weller SG, Heuser JE, McNiven MA. Cortactin is a component of clathrin-coated pits and participates in receptor-mediated endocytosis. Mol Cell Biol. (2003) 23:2162-70. doi: 10.1128/MCB.23.6.2162-2170.2003

64. Vidal-Quadras M, Gelabert-Baldrich M, Soriano-Castell D, Llado A, Rentero C, Calvo M, et al. Racl and calmodulin interactions modulate dynamics of ARF6-dependent endocytosis. Traffic. (2011) 12:187996. doi: 10.1111/j.1600-0854.2011.01274.x

65. Jarad G, Miner JH. Update on the glomerular filtration barrier. Curr Opin Nephrol Hypertens. (2009) 18:22632. doi: 10.1097/MNH.0b013e3283296044

66. Li Q, Gulati A, Lemaire M, Nottoli T, Bale A, Tufro A. Rho-GTPase activating protein myosin MYO9A identified as a novel candidate gene for monogenic focal segmental glomerulosclerosis. Kidney Int. (2021) 99:110217. doi: 10.1016/j.kint.2020.12.022

67. Mele $\mathrm{C}$, Iatropoulos $\mathrm{P}$, Donadelli $\mathrm{R}$, Calabria A, Maranta $\mathrm{R}$, Cassis $\mathrm{P}$, et al. MYO1E mutations and childhood familial focal segmental glomerulosclerosis. $N$ Engl J Med. (2011) 365:295-306. doi: 10.1056/NEJMoa1101273

68. Brown EJ, Schlondorff JS, Becker DJ, Tsukaguchi H, Tonna SJ, Uscinski $\mathrm{AL}$, et al. Mutations in the formin gene INF2 cause focal segmental glomerulosclerosis. Nat Genet. (2010) 42:72-6. doi: 10.1038/ng.505

69. Schneider R, Deutsch K, Hoeprich GJ, Marquez J, Hermle T, Braun DA, et al. DAAM2 variants cause nephrotic syndrome via actin dysregulation. Am J Hum Genet. (2020) 107:1113-28. doi: 10.1016/j.ajhg.2020.11.008

70. Kaplan JM, Kim SH, North KN, Rennke H, Correia LA, Tong $\mathrm{HQ}$, et al. Mutations in ACTN4, encoding alpha-actinin-4, cause familial focal segmental glomerulosclerosis. Nat Genet. (2000) 24:2516. doi: $10.1038 / 73456$

71. Kim JM, Wu H, Green G, Winkler CA, Kopp JB, Miner JH, et al. CD2-associated protein haploinsufficiency is linked to glomerular disease susceptibility. Science. (2003) 300:1298-300. doi: 10.1126/science.1081068

72. Hall G, Lane BM, Khan K, Pediaditakis I, Xiao J, Wu G, et al. The human FSGS-Causing ANLN R431C mutation induces dysregulated PI3K/AKT/mTOR/Racl signaling in podocytes. J Am Soc Nephrol. (2018) 29:2110-22. doi: 10.1681/ASN.2017121338

73. Akamatsu M, Vasan R, Serwas D, Ferrin MA, Rangamani P, Drubin DG. Principles of self-organization and load adaptation by the actin cytoskeleton during clathrin-mediated endocytosis. Elife. (2020) 9:e49840. doi: 10.7554/eLife.49840

74. Merrifield CJ, Qualmann B, Kessels MM, Almers W. Neural wiskott aldrich syndrome protein (N-WASP) and the Arp2/3 complex are recruited to sites of clathrin-mediated endocytosis in cultured fibroblasts. Eur J Cell Biol. (2004) 83:13-8. doi: 10.1078/0171-9335-00356

75. Collins A, Warrington A, Taylor KA, Svitkina T. Structural organization of the actin cytoskeleton at sites of clathrin-mediated endocytosis. Curr Biol. (2011) 21:1167-75. doi: 10.1016/j.cub.2011.05.048

76. Sever S, Altintas MM, Nankoe SR, Moller CC, Ko D, Wei C, et al. Proteolytic processing of dynamin by cytoplasmic cathepsin L is a mechanism for proteinuric kidney disease. J Clin Invest. (2007) 117:2095104. doi: 10.1172/JCI32022

77. Ferguson SM, Raimondi A, Paradise S, Shen H, Mesaki K, Ferguson A, et al. Coordinated actions of actin and BAR proteins upstream of dynamin at endocytic clathrin-coated pits. Dev Cell. (2009) 17:81122. doi: 10.1016/j.devcel.2009.11.005

78. Khalil R, Koop K, Kreutz R, Spaink HP, Hogendoorn PC, Bruijn JA, et al. Increased dynamin expression precedes proteinuria in glomerular disease. $J$ Pathol. (2019) 247:177-85. doi: 10.1002/path.5181

79. Altintas MM, Reiser J. More expression, less function: cleaved dynamin in glomerular kidney disease. J Pathol. (2019) 247:4135. doi: 10.1002/path.5217

80. Grassart A, Cheng AT, Hong SH, Zhang F, Zenzer N, Feng Y, et al. Actin and dynamin2 dynamics and interplay during clathrin-mediated endocytosis. $J$ Cell Biol. (2014) 205:721-35. doi: 10.1083/jcb.201403041
81. Krueger EW, Orth JD, Cao H, McNiven MA. A dynamin-cortactin-Arp $2 / 3$ complex mediates actin reorganization in growth factor-stimulated cells. $\mathrm{Mol}$ Biol Cell. (2003) 14:1085-96. doi: 10.1091/mbc.e02-08-0466

82. Gu C, Yaddanapudi S, Weins A, Osborn T, Reiser J, Pollak M, et al. Direct dynamin-actin interactions regulate the actin cytoskeleton. EMBO J. (2010) 29:3593-606. doi: 10.1038/emboj.2010.249

83. Schiffer M, Teng B, Gu C, Shchedrina VA, Kasaikina M, Pham VA, et al. Pharmacological targeting of actin-dependent dynamin oligomerization ameliorates chronic kidney disease in diverse animal models. Nat Med. (2015) 21:601-9. doi: 10.1038/nm.3843

84. Gu C, Lee HW, Garborcauskas G, Reiser J, Gupta V, Sever S. Dynamin autonomously regulates podocyte focal adhesion maturation. J Am Soc Nephrol. (2017) 28:446-51. doi: 10.1681/ASN.2016010008

85. La TM, Tachibana H, Li SA, Abe T, Seiriki S, Nagaoka H, et al. Dynamin 1 is important for microtubule organization and stabilization in glomerular podocytes. FASEB J. (2020) 34:16449-63. doi: 10.1096/fj.202001240RR

86. Chandrasekar I, Goeckeler ZM, Turney SG, Wang P, Wysolmerski RB, Adelstein RS, et al. Nonmuscle myosin II is a critical regulator of clathrinmediated endocytosis. Traffic. (2014) 15:418-32. doi: 10.1111/tra.12152

87. Grahammer F, Wigge C, Schell C, Kretz O, Patrakka J, Schneider $\mathrm{S}$, et al. A flexible, multilayered protein scaffold maintains the slit in between glomerular podocytes. JCI Insight. (2016) 1:e86177. doi: 10.1172/jci.insight.86177

88. Cheng J, Grassart A, Drubin DG. Myosin 1E coordinates actin assembly and cargo trafficking during clathrin-mediated endocytosis. Mol Biol Cell. (2012) 23:2891-904. doi: 10.1091/mbc.e11-04-0383

89. Navines-Ferrer A, Martin M. Long-tailed unconventional class I myosins in health and disease. Int J Mol Sci. (2020) 21:2555. doi: 10.3390/ijms21072555

90. Shen H, Bao Y, Feng C, Fu H, Mao J. Overexpression of Myole promotes albumin endocytosis by mouse glomerular podocytes mediated by Dynamin. PeerJ. (2020) 8:e8599. doi: 10.7717/peerj.8599

91. Bywaters BC, Rivera GM. Nck adaptors at a glance. J Cell Sci. (2021) 134:jcs258965. doi: 10.1242/jcs.258965

92. Martin CE, New LA, Phippen NJ, Keyvani Chahi A, Mitro AE, Takano $\mathrm{T}$, et al. Multivalent nephrin-Nck interactions define a threshold for clustering and tyrosine-dependent nephrin endocytosis. J Cell Sci. (2020) 133:jcs236877. doi: 10.1242/jcs.236877

93. Wunderlich L, Farago A, Downward J, Buday L. Association of Nck with tyrosine-phosphorylated SLP-76 in activated T lymphocytes. Eur J Immunol. (1999) 29:106875. doi: 10.1002/(SICI)1521-4141(199904)29:04\&lt;1068::AIDIMMU1068\&gt;3.0.CO;2-P

94. Humphries AC, Donnelly SK, Way M. Cdc42 and the Rho GEF intersectin-1 collaborate with Nck to promote N-WASP-dependent actin polymerisation. J Cell Sci. (2014) 127(Pt 3):673-85. doi: 10.1242/jcs.141366

95. Gigante M, Pontrelli P, Montemurno E, Roca L, Aucella F, Penza R, et al. CD2AP mutations are associated with sporadic nephrotic syndrome and focal segmental glomerulosclerosis (FSGS). Nephrol Dial Transplant. (2009) 24:1858-64. doi: 10.1093/ndt/gfn712

96. Cummins TD, Wu KZL, Bozatzi P, Dingwell KS, Macartney TJ, Wood NT, et al. PAWS1 controls cytoskeletal dynamics and cell migration through association with the SH3 adaptor CD2AP. J Cell Sci. (2018) 131:jcs202390. doi: 10.1101/106971

97. Lowik MM, Groenen PJ, Pronk I, Lilien MR, Goldschmeding R, Dijkman HB, et al. Focal segmental glomerulosclerosis in a patient homozygous for a CD2AP mutation. Kidney Int. (2007) 72:1198203. doi: $10.1038 /$ sj.ki.5002469

98. Park BC, Yim YI, Zhao X, Olszewski MB, Eisenberg E, Greene LE. The clathrin-binding and J-domains of GAK support the uncoating and chaperoning of clathrin by Hsc70 in the brain. J Cell Sci. (2015) 128:381121. doi: $10.1242 /$ jcs. 171058

99. Greener T, Zhao X, Nojima H, Eisenberg E, Greene LE. Role of cyclin Gassociated kinase in uncoating clathrin-coated vesicles from non-neuronal cells. J Biol Chem. (2000) 275:1365-70. doi: 10.1074/jbc.275.2.1365

100. Boulant S, Kural C, Zeeh JC, Ubelmann F, Kirchhausen T. Actin dynamics counteract membrane tension during clathrin-mediated endocytosis. Nat Cell Biol. (2011) 13:1124-31. doi: 10.1038/ncb2307 
101. Swiatecka-Urban A. Membrane trafficking in podocyte health and disease. Pediatr Nephrol. (2013) 28:1723-37. doi: 10.1007/s00467-012-2281-y

102. Bai L, Zhuang J, Zhang C, Lu C, Tian X, Jiang H. Case report: the monogenic familial steroid-resistant nephrotic syndrome caused by a novel missense mutation of NPHS2 Gene A593C in a chinese family. Front Pediatr. (2021) 9:692727. doi: 10.3389/fped.2021.692727

103. Fukuda H, Hidaka T, Takagi-Akiba M, Ichimura K, Oliva Trejo JA, Sasaki Y, et al. Podocin is translocated to cytoplasm in puromycin aminonucleoside nephrosis rats and in poor-prognosis patients with IgA nephropathy. Cell Tissue Res. (2015) 360:391-400. doi: 10.1007/s00441-014-2100-9

104. Sasaki Y, Hidaka T, Ueno T, Akiba-Takagi M, Oliva Trejo JA, Seki T, et al. Sorting Nexin 9 facilitates podocin endocytosis in the injured podocyte. Sci Rep. (2017) 7:43921. doi: 10.1038/srep43921

105. Patrakka J, Kestila M, Wartiovaara J, Ruotsalainen V, Tissari P, Lenkkeri $\mathrm{U}$, et al. Congenital nephrotic syndrome (NPHS1): features resulting from different mutations in Finnish patients. Kidney Int. (2000) 58:97280. doi: 10.1046/j.1523-1755.2000.00254.x

106. Ruotsalainen V, Ljungberg P, Wartiovaara J, Lenkkeri U, Kestila M, Jalanko H, et al. Nephrin is specifically located at the slit diaphragm of glomerular podocytes. Proc Natl Acad Sci U S A. (1999) 96:79627. doi: $10.1073 /$ pnas. 96.14 .7962

107. Tossidou I, Teng B, Drobot L, Meyer-Schwesinger C, Worthmann K, Haller $\mathrm{H}$, et al. CIN85/RukL is a novel binding partner of nephrin and podocin and mediates slit diaphragm turnover in podocytes. J Biol Chem. (2010) 285:25285-95. doi: 10.1074/jbc.M109.087239

108. Dumont V, Tolvanen TA, Kuusela S, Wang H, Nyman TA, Lindfors $S$, et al. PACSIN2 accelerates nephrin trafficking and is up-regulated in diabetic kidney disease. FASEB J. (2017) 31:3978-90. doi: 10.1096/fj.20160 $1265 \mathrm{R}$

109. Teng B, Duong M, Tossidou I, Yu X, Schiffer M. Role of protein kinase C in podocytes and development of glomerular damage in diabetic nephropathy. Front Endocrinol (Lausanne). (2014) 5:179. doi: 10.3389/fendo.2014.00179

110. Martin CE, Petersen KA, Aoudjit L, Tilak M, Eremina V, Hardy WR, et al. ShcA adaptor protein promotes nephrin endocytosis and is upregulated in proteinuric nephropathies. J Am Soc Nephrol. (2018) 29:92103. doi: 10.1681/ASN.2017030285

111. Liu Y, Su H, Ma C, Ji D, Zheng X, Wang P, et al. IQGAP1 mediates podocyte injury in diabetic kidney disease by regulating nephrin endocytosis. Cell Signal. (2019) 59:13-23. doi: 10.1016/j.cellsig.2019.03.009

112. Espiritu EB, Jiang $H$, Moreau-Marquis $S$, Sullivan $M$, Yan $K$, Beer Stolz D, et al. The human nephrin Y (1139) RSL motif is essential for podocyte foot process organization and slit diaphragm formation during glomerular development. J Biol Chem. (2019) 294:10773-88. doi: 10.1074/jbc.RA119.008235

113. Jones N, Blasutig IM, Eremina V, Ruston JM, Bladt F, Li H, et al. Nck adaptor proteins link nephrin to the actin cytoskeleton of kidney podocytes. Nature. (2006) 440:818-23. doi: 10.1038/nature04662

114. Feng D. Phosphorylation of key podocyte proteins and the association with proteinuric kidney disease. Am J Physiol Renal Physiol. (2020) 319:F284F91. doi: 10.1152/ajprenal.00002.2020

115. Qin XS, Tsukaguchi H, Shono A, Yamamoto A, Kurihara H, Doi T. Phosphorylation of nephrin triggers its internalization by raft-mediated endocytosis. J Am Soc Nephrol. (2009) 20:2534-45. doi: 10.1681/ASN.2009010011

116. Heiden S, Siwek R, Lotz ML, Borkowsky S, Schroter R, Nedvetsky P, et al. Apical-basal polarity regulators are essential for slit diaphragm assembly and endocytosis in Drosophila nephrocytes. Cell Mol Life Sci. (2021) 78:365772. doi: 10.1007/s00018-021-03769-y

117. Itoh M, Nakadate K, Matsusaka T, Hunziker W, Sugimoto H. Effects of the differential expression of ZO-1 and ZO-2 on podocyte structure and function. Genes Cells. (2018) 23:546-56. doi: 10.1111/gtc.12598

118. Lausecker F, Tian X, Inoue K, Wang Z, Pedigo CE, Hassan H, et al. Vinculin is required to maintain glomerular barrier integrity. Kidney Int. (2018) 93:643-55. doi: 10.1016/j.kint.2017.09.021

119. Mysh M, Poulton JS. The basolateral polarity module promotes slit diaphragm formation in drosophila nephrocytes, a model of vertebrate podocytes. J Am Soc Nephrol. (2021) 32:140924. doi: 10.1681/ASN.2020071050
120. Nishibori Y, Liu L, Hosoyamada M, Endou H, Kudo A, Takenaka H, et al. Disease-causing missense mutations in NPHS2 gene alter normal nephrin trafficking to the plasma membrane. Kidney Int. (2004) 66:175565. doi: 10.1111/j.1523-1755.2004.00898.x

121. Philippe A, Weber S, Esquivel EL, Houbron C, Hamard G, Ratelade J, et al. A missense mutation in podocin leads to early and severe renal disease in mice. Kidney Int. (2008) 73:1038-47. doi: 10.1038/ki.2008.27

122. Tojo A, Hatakeyama S, Kinugasa S, Fukuda S, Sakai T. Enhanced podocyte vesicle transport in the nephrotic rat. Med Mol Morphol. (2017) 50:8693. doi: $10.1007 / \mathrm{s} 00795-016-0151-6$

123. Schiess IM, Hammer A, Kattler V, Gess B, Theilig F, Witzgall $\mathrm{R}$, et al. Intravital imaging reveals angiotensin ii-induced transcytosis of albumin by podocytes. J Am Soc Nephrol. (2016) 27:731-44. doi: 10.1681/ASN.2014111125

124. Moriyama T, Hasegawa F, Miyabe Y, Akiyama K, Karasawa K, Uchida $\mathrm{K}$, et al. Intracellular trafficking pathway of albumin in glomerular epithelial cells. Biochem Biophys Res Commun. (2021) 574:97-103. doi: 10.1016/j.bbrc.2021.08.043

125. Shi Y, Wang C, Zhou X, Li Y, Ma Y, Zhang R, et al. Downregulation of PTEN promotes podocyte endocytosis of lipids aggravating obesityrelated glomerulopathy. Am J Physiol Renal Physiol. (2020) 318:F589F99. doi: 10.1152/ajprenal.00392.2019

126. Chung JJ, Huber TB, Godel M, Jarad G, Hartleben B, Kwoh C, et al. Albuminassociated free fatty acids induce macropinocytosis in podocytes. $J$ Clin Invest. (2015) 125:2307-16. doi: 10.1172/JCI79641

127. Solanki AK, Arif E, Morinelli T, Wilson RC, Hardiman G, Deng P, et al. A novel CLCN5 mutation associated with focal segmental glomerulosclerosis and podocyte injury. Kidney Int Rep. (2018) 3:144353. doi: 10.1016/j.ekir.2018.06.003

128. Ma L, Shelness GS, Snipes JA, Murea M, Antinozzi PA, Cheng D, et al. Localization of APOL1 protein and mRNA in the human kidney: nondiseased tissue, primary cells, and immortalized cell lines. J Am Soc Nephrol. (2015) 26:339-48. doi: 10.1681/ASN.2013091017

129. Khatua AK, Cheatham AM, Kruzel ED, Singhal PC, Skorecki K, Popik W. Exon 4-encoded sequence is a major determinant of cytotoxicity of apolipoprotein L1. Am J Physiol Cell Physiol. (2015) 309:C2237. doi: 10.1152/ajpcell.00384.2014

130. Lei CT, Wei YH, Tang H, Wen Q, Ye C, Zhang C, et al. PKCalpha triggers EGFR ubiquitination, endocytosis and ERK activation in podocytes stimulated with high glucose. Cell Physiol Biochem. (2017) 42:28194. doi: $10.1159 / 000477329$

131. Inoue K, Tian X, Velazquez H, Soda K, Wang Z, Pedigo CE, et al. Inhibition of endocytosis of clathrin-mediated Angiotensin II receptor type 1 in podocytes augments glomerular injury. J Am Soc Nephrol. (2019) 30:230720. doi: 10.1681/ASN.2019010053

132. Soriano-Castell D, Chavero A, Rentero C, Bosch M, Vidal-Quadras M, Pol A, et al. ROCK1 is a novel Rac1 effector to regulate tubular endocytic membrane formation during clathrin-independent endocytosis. Sci Rep. (2017) 7:6866. doi: 10.1038/s41598-017-07130-x

133. Kreidberg JA, Donovan MJ, Goldstein SL, Rennke H, Shepherd $\mathrm{K}$, Jones RC, et al. Alpha 3 beta 1 integrin has a crucial role in kidney and lung organogenesis. Development. (1996) 122:3537-47. doi: 10.1242/dev.122.11.3537

134. Pozzi A, Jarad G, Moeckel GW, Coffa S, Zhang X, Gewin $\mathrm{L}$, et al. Betal integrin expression by podocytes is required to maintain glomerular structural integrity. Dev Biol. (2008) 316:288-301. doi: 10.1016/j.ydbio.2008.01.022

135. Caliva MJ, Yang WS, Young-Robbins S, Zhou M, Yoon H, Matter $\mathrm{ML}$, et al. Proteomics analysis identifies PEA-15 as an endosomal phosphoprotein that regulates alpha5betal integrin endocytosis. Sci Rep. (2021) 11:19830. doi: 10.1038/s41598-021-99348-z

136. Kobayashi N, Ueno T, Ohashi K, Yamashita H, Takahashi Y, Sakamoto $\mathrm{K}$, et al. Podocyte injury-driven intracapillary plasminogen activator inhibitor type 1 accelerates podocyte loss via uPAR-mediated beta1integrin endocytosis. Am J Physiol Renal Physiol. (2015) 308:F61426. doi: 10.1152 /ajprenal.00616.2014

137. Moreno-Layseca P, Jantti NZ, Godbole R, Sommer C, Jacquemet $G$, Al-Akhrass $H$, et al. Cargo-specific recruitment 
in clathrin- and dynamin-independent endocytosis. Nat Cell Biol. (2021) 23:1073-84. doi: 10.1101/2020.10.05.32 3295

138. Wu L, Chen $\mathrm{M}$, Mao $\mathrm{H}$, Wang $\mathrm{N}$, Zhang $\mathrm{B}$, Zhao $\mathrm{X}$, et al. Albumin-based nanoparticles as methylprednisolone carriers for targeted delivery towards the neonatal $\mathrm{Fc}_{\mathrm{c}}$ receptor in glomerular podocytes. Int J Mol Med. (2017) 39:851-60. doi: 10.3892/ijmm.2017. 2902

139. Groener M WY, Cross E, Tian X, Ebenezer K, Baik E, Pedigo CE, et al. Identification of podocyte cargo proteins by proteomic analysis of clathrincoated vesicles. Kidney360. (2020) 1:480-90. doi: 10.34067/KID.0000212020

Conflict of Interest: The authors declare that the research was conducted in the absence of any commercial or financial relationships that could be construed as a potential conflict of interest.
The handling Editor declared a shared affiliation with the authors at the time of review.

Publisher's Note: All claims expressed in this article are solely those of the authors and do not necessarily represent those of their affiliated organizations, or those of the publisher, the editors and the reviewers. Any product that may be evaluated in this article, or claim that may be made by its manufacturer, is not guaranteed or endorsed by the publisher.

Copyright (c) 2022 Tian, Bunda and Ishibe. This is an open-access article distributed under the terms of the Creative Commons Attribution License (CC BY). The use, distribution or reproduction in other forums is permitted, provided the original author(s) and the copyright owner(s) are credited and that the original publication in this journal is cited, in accordance with accepted academic practice. No use, distribution or reproduction is permitted which does not comply with these terms. 